\title{
Relation between breast cancer and high glycemic index or glycemic load: A meta-analysis of prospective cohort studies.
}

\section{Running title: Glycemic load and breast cancer}

Patrick Mullie (1), Alice Koechlin (1), Mathieu Boniol (1), Philippe Autier (1,2), Peter Boyle (1)

1. International Prevention Research Institute, 95 cours Lafayette, 69006 Lyon, France

2. Address for correspondence and reprint requests: Dr Philippe Autier, International Prevention Research Institute, 95 cours Lafayette, 69006 Lyon, France. E-mail: philippe.autier@i-pri.org, Telephone: 00324721711 99, Fax: 0032472171190 


\begin{abstract}
(n=196)
Breast cancer is the commonest form of cancer in women worldwide. It has been suggested that chronic hyperinsulinemia associated with insulin resistance plays a role in breast cancer etiology. To test the hyperinsulinemia hypothesis, a dietary pattern associated with a high glycemic index and glycemic load, both proxies for chronic hyperinsulinemia, should be associated with an increased risk of breast cancer. A meta-analysis restricted to prospective studies was undertaken using a random effects model with tests for statistical significance, publication bias and heterogeneity. The metric for analysis was the risk of breast cancer in the highest relative to the lowest glycemic index and glycemic load dietary pattern. A dietary pattern with a high glycemic index was associated with a summary relative risk (SRR) of 1.05 (95\% CI: 1.00; 1.11$)$, and a high glycemic load with a SRR of 1.06 (95\% CI: 1.00; 1.13). Adjustments for body mass index, physical activity and other lifestyle factors did not influence the SRR, nor did menopausal status and estrogen receptor status of the tumor. In conclusion, the current evidence supports a modest association between a dietary pattern with high glycemic index or glycemic load and the risk of breast cancer.
\end{abstract}

Keywords: hyperinsulinemia, nutritional epidemiology, prevention 


\section{Introduction}

Breast cancer is the commonest form of cancer in women worldwide and the incidence is still increasing, even in the developing world, due to a number of factors including the increase in life expectancy, the increase in urbanization and the adoption of western lifestyles and dietary patterns (WCRF 2007). It has been suggested that chronic hyperinsulinemia associated with insulin resistance plays a role in the etiology of cancer in general. Insulin resistance is characterized by a resistance of cells to the action of insulin with slow cellular uptake of glucose. The direct consequence of the insulin resistance is a raise in serum glucose concentration that stimulates insulin secretion. Insulin is a mitogenic agent, and chronic hyperinsulinemia has been related to down-regulation of insulin-like growth factor binding protein-1 and 2 , with an increase in insulin-like growth factor 1 (IGF-1) as consequence (Conover et al. 1992, Papa and Belfiore 1996, Li et al. 2001). This increase in bioavailable insulin and IGF-1 could induce mutagenic changes in the cellular environment.

If the hyperinsulinemia hypothesis plays a role in the etiology of breast cancer, determinants of insulin secretion could be related to the etiology of breast cancer. A proxy-indicator of insulinemia is the dietary glycemic index. This index, developed by Jenkins et al. (Jenkins et al. 1981), represents the postprandial glycemic increase of a nutrient with carbohydrates compared with a reference, which is pure glucose or white bread. The glycemic index of a nutrient is equal to the serum glucose response two hours after intake of 50 grams of the tested nutrient divided by the serum glucose response two hours after intake of 50 grams of carbohydrates from glucose or white bread as reference. The ratio is multiplied by 100 for obtaining a proportion, and each percent is equated to a "unit" of glycemic index. Each nutrient has its own specific glycemic index. Most fruits, vegetables, legumes, intact grains and nuts have a glycemic index lower than 55. Sucrose, grapes, whole wheat products have a 
glycemic index between 56 and 69 . White bread, white rice and potatoes have a glycemic index of more than 70 . Some breakfast cereals have a glycemic index of more than 100, which denotes a greater ability than pure glucose to trigger an insulin secretion (Foster-Powell et al. 2002). In general, if a carbohydrate containing nutrient is quickly broken down during digestion, the glycemic index will be higher due to fast release of glucose in the blood stream, and, as a consequence, the insulin demand will increase. Hence, compared to a low glycemic index diet, a high glycemic index diet is characterized by the secretion of greater amounts of insulin. Hence, if chronic hyperinsulinemia would be associated with breast cancer occurrence, the risk of being diagnosed with this cancer should increase with the glycemic index.

The glycemic load was developed to reflect the quality and the quantity of the consumed carbohydrates by multiplying the consumed carbohydrates with their respective glycemic index. The glycemic load is equal to the glycemic index divided by 100 and multiplied by the weight of consumed carbohydrates. The glycemic load is expressed in grams per day. The glycemic load is usually considered a better indicator than glycemic index of the postprandial glucose and insulin secretion because it takes into account quantities of carbohydrated nutrients that are eaten (Salmerón et al. 1997).

Prospective cohort studies usually measure nutritional exposure using food frequency questionnaires. These questionnaires typically measure how often predefined nutrients are consumed. Using a reference table with glycemic indices that were measured for each nutrient during human experiments (Foster-Powell et al. 2002), and using the weighted sum of consumed carbohydrates from the food frequency questionnaire, the glycemic index and load of a dietary pattern can be obtained by calculation. 
To investigate the relation between glycemic index, glycemic load and breast cancer, we performed a systematic review with a meta-analysis using available data from prospective studies relating glycemic index and glycemic load to the incidence of breast cancer. In addition, an analysis stratified by estrogen receptor status of the tumor was performed.

\section{Materials and Methods}

Pre-defined protocol

Systematic literature search and quantitative analysis were planned, conducted and reported following MOOSE guidelines regarding metaanalysis of observational studies (Stroup et al. 2000).

\section{Literature search for the meta-analysis}

Published reports until 31/12/2011 were obtained from the following databases using validated search strategies: PUBMED (http://www.ncbi.nlm.nih.gov/entrez/query.fcgi), Ovid Medline (Ovid Technologies, Inc., New York), EMBASE (Elsevier, Amsterdam, the Netherlands), ISI Web of Knowledge (Thomson Scientific Technical Support, New York) and the Cochrane collaboration databases (www.cochrane.org). All searches used MeSH index terms: "breast neoplasm" or "neoplasm", each combined with "glycemic index" or "glycemic load". We also performed manual searches of references cited in the retrieved articles and preceding reviews on the topic. Because case-control studies have several methodological limitations, we restricted our study to prospective cohort studies. For instance, recall bias can influence retrospective data collected using food-frequency questionnaires. 
Articles eligible for the meta-analysis had to meet the following main criteria: (i) report data on incident cases of breast cancer, being in situ or invasive, (ii) report on measurement of glycemic index or glycemic load, (iii) have a prospective cohort or nested case-control design, (iv) published until 31/12/2011, and (v) published in English. There was no restriction on geographical location of studies.

We screened titles and looked at abstracts when the title suggested a study possibly meeting the main criteria. If the abstract content was relevant, full copies of articles were retrieved and fully read by at least two co-authors.

Review articles not reporting original data were also excluded but checked for references.

\section{Data extraction for the meta-analysis}

Data extraction was done by one co-author in a pre-defined database. The resulting table was verified by another author and by the statistician who performed the meta-analysis. Discordances were checked by a third author. The most adjusted risk estimates were extracted.

The following data were retrieved from the publications: first author name, year of publication, study type, number of cases, number of controls or total persons or person-years, stratification used within the analyses, exposure, most adjusted risk estimates and $95 \%$ confidence interval, as well as relative risks not adjusted and adjusted for adiposity (usually the body mass index [BMI])..

\section{Statistical analysis}

Most studies reported relative risks (RR) and 95\% confidence interval between glycemic index or glycemic load and breast cancer in tertiles or quintiles of glycemic index and glycemic load. For Giles's study (Giles et al. 2006), the RR was reported for an increase of 1 standard deviation. To use a RR compatible in term of definition with others, i.e. based on the values high versus low glycemic index or glycemic load, we computed 
the risk for an increase of $2.56 \mathrm{SD}$ to be included in the meta-analysis. This would correspond to the difference between the 10 th percentile to the 90th percentile of a normal distribution and then could be compared to RR computed from high versus low quintiles of a distribution of glycemic index or glycemic load.

The meta-analysis was done on the risks as reported in the highest category of glycemic index and glycemic load versus the lowest (the referent category), as high GI and GL levels are supposed to be associated with the highest risk of breast cancer.

A meta-analysis using a random effects model with tests for statistical significance, publication bias and heterogeneity was performed. The aim was to evaluate the potential relationship between glycemic index and glycemic load and the risk of developing breast cancer in women.

The various estimates of relative risk were log-transformed and the corresponding variance was computed from the $95 \%$ confidence intervals. From the transformed data, summary relative risk estimates (SRR) were calculated using a random effects model (van Houwelingen et al. 2002). Since the number of studies included was low, SRRs were obtained with maximum likelihood estimates and confidence intervals were based on t-distribution. Heterogeneity across studies was evaluated by Cochrane's Q and Higgins' $\mathrm{I}^{2}$, which represents the percentage of total variation across studies that are attributable to heterogeneity rather than to chance (Higgins and Thompson 2002). Sensitivity analyses were carried out to evaluate the influence of each study on the overall estimate from the meta-analysis.

Publication bias was evaluated graphically with a funnel plot; and we conducted three different tests for publication bias: the Begg test (rank correlation test, (Begg and Mazumdar 1994)), the Egger test (weighted linear regression test for the funnel plot asymmetry, (Egger et al. 1997)), and the Macaskill test (regression of $\log (\mathrm{RR})$ on the sample size, weighted by the inverse of the variance, (Macaskill et al. 2001)). Since the 
sensitivity of Begg and Egger tests is low in meta-analyses where less than 20 estimates are included, the Macaskill test is the preferred approach.

To investigate sources of heterogeneity, separate analyses were performed for studies where adjustments had, and had not, been made, for preand postmenopausal women, and for estrogen receptor positive and negative breast cancers.

All analyses were conducted with R statistical package (version 2.13.1, GNU General Public License, 2011) and package metaphor (Viechtbauer 2010).

\section{Results}

In total 14 prospective cohort studies were identified which fulfilled the criteria for inclusion in the meta-analysis (Cho et al. 2003, Jonas et al. 2003, Frazier et al. 2004, Higginbotham et al. 2004, Holmes et al. 2004, Nielsen et al. 2005, Silvera et al. 2005, Giles et al. 2006, Sieri et al. 2007, Lajous et al. 2008, Larsson et al. 2009, Wen et al. 2009, Linos et al. 2010, Shikany et al. 2011) (Figure 1). Linos et al. (Linos et al. 2010) and Higginbotham et al. (Higginbotham et al. 2004) were excluded because the same cohorts were used in Cho et al. (Cho et al. 2003) and Shikany et al. (Shikany et al. 2011), respectively. However, Linos et al. (Linos et al. 2010) selected only data from premenopausal women, so in a sensitivity analysis Cho et al. (Cho et al. 2003) was replaced by Linos et al. (Linos et al. 2010).

Table 1 presents the characteristics of the cohort studies included in the meta-analysis (Cho et al. 2003, Jonas et al. 2003, Frazier et al. 2004, Holmes et al. 2004, Nielsen et al. 2005, Silvera et al. 2005, Giles et al. 2006, Sieri et al. 2007, Lajous et al. 2008, Larsson et al. 2009, Wen et al. 2009, Shikany et al. 2011). Six cohort studies were conducted in North America (Cho et al. 2003, Jonas et al. 2003, Frazier et al. 2004, Holmes et 
al. 2004, Silvera et al. 2005, Shikany et al. 2011), 4 in Europe (Nielsen et al. 2005, Sieri et al. 2007, Lajous et al. 2008, Larsson et al. 2009), 1 in Australia (Giles et al. 2006) and 1 in Asia (China) (Wen et al. 2009). The meta-analysis included 20,973 breast cancer cases and 773,971 cohort subjects. Two studies were conducted on the same cohort, i.e. Cho et al. (Cho et al. 2003) and Frazier et al. (Frazier et al. 2004). However, Cho et al. (Cho et al. 2003) was limited to premenopausal women, and Frazier et al. (Frazier et al. 2004) related adolescent diet to breast cancer.

The risk estimates observed in the cohort study of Sieri et al. (Sieri et al. 2007) are higher than the other cohorts, with a RR $=1.57(95 \%$ CI: 1.04 ; 2.36) for glycemic index and a $\mathrm{RR}=2.53(95 \% \mathrm{CI}: 1.54 ; 4.16)$ for glycemic load.

The summary relative risk (SRR) for breast cancer for a dietary pattern with a high glycemic index was 1.05 (95\% CI: 1.00; 1.11)(Figure 2). The $\mathrm{I}^{2}$ was $20 \%$, the percentage of heterogeneity which could not be explained by chance. Tests for publication bias were non-significant indicating that there was no publication bias.

Sensitivity analysis leaving one out at a time, excluding Cho et al. (Cho et al. 2003) and including Linos et al. (Linos et al. 2010) produced no major increased or decreased risk (data not shown).

The SRR of breast cancer for a dietary pattern with a high glycemic load was 1.06 (95\% CI: 1.00; 1.13) (Figure 3). The $\mathrm{I}^{2}$ was $55 \%$, indicating substantial heterogeneity in findings between studies. Tests for publication bias were non-significant indicating that there was no publication bias. 
Table 2 displays the age-adjusted and fully-adjusted SRR for glycemic index and glycemic load. Adjustments for body mass index, physical activity and other lifestyle factors did not influence the SRR, nor did menopausal status and estrogen receptor status. The SRRs of 8 studies that reported relative risks unadjusted and adjusted for BMI (and other factors) were similar.

\section{Discussion}

Our meta-analysis of 12 cohort studies involving 20,973 breast cancer cases and 773,971 cohort members shows that compared to women with low glycemic index or glycemic load dietary patterns, women with a high glycemic index or glycemic load dietary patterns have a small 5 to $6 \%$ increase of the risk of breast cancer.

Three meta-analyses about glycemic index, glycemic load and breast cancer were published in the last years (Barclay et al. 2008, Mulholland et al. 2008, Dong and Qin 2011), and the most recent one (Dong and Qin 2011) did not include three cohort studies (Frazier et al. 2004, Nielsen et al. 2005, Giles et al. 2006). Our results are in agreement with previously published meta-analyses (Barclay et al. 2008, Mulholland et al. 2008, Dong and Qin. 2011), but inclusion of most recent cohorts decreased the SRRs of 1.08 found by Dong et al., (Dong and Qin 2011) to 1.05.

Risk estimates of individual cohort studies were quite homogenous, except for Sieri et al. (Sieri et al. 2007), who obtained relative risks of 1.57 (95\% CI: $1.04 ; 2.36)$ and 2.53 (95\% CI: 1.54; 4.16), for the glycemic index and glycemic load, respectively. Sieri et al. (Sieri et al. 2007) was the cohort study with the lowest number of cases $(n=289)$ and participants $(n=8,926)$. Moreover, all cohort studies used the Foster-Powell reference tables for glycemic index and glycemic load (Foster-Powell and Miller 1995, Foster-Powell 2002), but the study of Sieri et al. (Sieri et 
al. 2007) that used locally established glycemic index tables with values specific for Italian food. The Inter-Laboratory Study (Wolever et al. 2008) demonstrated that glycemic indices measured by different laboratories can vary widely and thus the one cannot dismiss that the outlying values obtained by the Sieri et al. (Sieri et al. 2007) study could be due to inter-laboratory variations.

Can the small magnitude of the risks associated with glycemic index and glycemic load be interpreted as a refutation of the hyperinsulinemia hypothesis? Firstly, one must question if the measured glycemic index and glycemic load are accurate proxy indicator for lifelong hyperinsulinemia secretion. Secondly, the small observed effect size could be due to residual confounding rather than to the glycemic index or glycemic load themselves.

As stated by Pi-Sunyer (Pi-Sunyer 2002), people do not eat only carbohydrates but meals with more than one macronutrient. A mixed meal of carbohydrates, proteins and fats will produce different types of changes in serum glucose concentrations, what will in turn induce different insulin secretion patterns. This implies that the experimentally measured glycemic index after single nutrient ingestion could be different if carbohydrates were ingested during a meal. Intra-individual variations in the measurement of glycemic index are substantial (e.g., index measured in the morning or in the evening), often approaching the inter-individual variations observed in prospective studies (Pi-Sunyer 2002). In an experiment, Dodd et al. (Dodd and Qin 2011) compared the observed glycemic index of a meal with a calculated value based on a food frequency questionnaire. Glycemic indices are normally tested for individual nutrients, whereas glycemic indices of dietary patterns are calculated using weighted sum of carbohydrates entering in the composition of the various food items reported in the questionnaire. The aim of the experiment of Dodd et al. (Dodd and Qin 2011) was to evaluate the accuracy of this calculated value. The glycemic indices of seven nutrients 
were tested in 30 healthy people. The same nutrients were combined in meals, and the mean glycemic indices of the meals were determined by calculation from the individual glycemic indices and by direct measurements. They found that formulas used to calculate the glycemic indices have an unpredictable overestimation of 22 to $50 \%$ compared with the test values, which implies a low validity of calculated values. For example, a potato meal had a calculated and measured glycemic index of 63 and 53, respectively. For a rice meal these figures were 51 and 38 , and for a spaghetti meal, 54 and 38. This shows the limited reliability of calculated glycemic indices based on food frequency questionnaires. Prospective studies included many potential confounders in multivariate models predicting risk of breast cancer, but not all studies adjusted for physical activity and educational level. These two variables are powerful determinants of a healthier dietary pattern with possible lower glycemic index or glycemic load, and residual confounding cannot be excluded.

All cohort studies used food frequency questionnaires to record nutritional exposition at the start of the cohort. Multiple measurements of dietary exposure may attenuate the influence of random misclassification on food frequency records, but few studies collected data on dietary patterns more than once. Food frequency questionnaires used by most studies were not designed for assessing glycemic index and glycemic load of dietary patterns. Food frequency questionnaires are known to include a lower variety of food items than dietary records. The true ranges of glycemic index and glycemic load prevailing in a study population may thus not be fully appreciated if food frequency questionnaires are used. Moreover, food frequency questionnaires do not collect information of the way food items are combined during meals, what could have an influence on estimated glycemic index and glycemic load (Pi-Sunyer 2002). 
In conclusion, a weak association seems to exist between between glycemic index, glycemic load and breast cancer. This result could reflect an absence of a sound relationship between chronic hyperinsulinemia and breast cancer risk, or it could be due to the limited reliability of these indices. For testing the hyperinsulinemia hypothesis, more accurate biomarkers should be used.

\section{Declaration of interest}

The authors declare that they have no conflict of interest.

\section{Funding}

This study was part of works associated with an unrestricted research grant from Sanofi.

\section{Acknowledgements:}

This study was part of the research activities of the International Prevention Research Institute (iPRI) Research Group on Diabetes, Metabolic Disorders and Cancer, whose members are: P. Autier, A. Koechlin, M. Boniol, P. Mullie, P. Boyle, F. Valentini, K. Coppens, L-L. Fairley, M. Boniol-Rech, M. Pasterk, M. Smans, M-P. Curado, M. Bota (iPRI, Lyon, France); S. Gandini (European Institute of Oncology, Milan, Italy); Chris Robertson (Department of Mathematics and Statistics, University of Strathclyde, Glasgow, Scotland); Tongzhang Zheng, Yawei Zhang (Yale University School of Public Health, New Haven, Connecticut, United States of America); Geremia Bolli (Department of Internal Medicine and Oncology, S.M. Misericordia Hospital, University of Perugia, Perugia, Italy); J. Rosenstock (Dallas Diabetes and Endocrine Center, Dallas, United States of America). The authors have no conflict of interest to disclose. 


\section{References}

Barclay, AW., Petocz, P., McMillan-Price, J., Flood, VM., Prvan, T., Mitchell, P., and Brand-Miller, JC. (2008). Glycemic index, glycemic load, and chronic disease risk - a meta-analysis of observational studies. Am J Clin Nutr. 87 : 627-637.

Begg, CB., and Mazumdar, M. (1994). Operating characteristics of a rank correlation test for publication bias. Biometrics. 50 : $1088-1101$.

Cho, E., Spiegelman, D., Hunter, DJ., Chen, WY., Colditz, GA., and Willett; WC. (2003). Premenopausal dietary carbohydrate, glycemic index, glycemic load, and fiber in relation to risk of breast cancer. Cancer Epidemiol Biomarkers Prev.12 : 1153-1158.

Conover, CA., Lee, PD., Kanaley, JA., Clarkson, JT,. and Jensen MD. (1992). Insulin regulation of insulin-like growth factor binding protein-1 in obese and non-obese humans. J Clin Endocrinol Metab. 74 : 1355-1360.

Dodd, H., Williams, S., Brown, R., and Venn, B. (2011) Calculating meal glycemic index by using measured and published food values compared with directly measured meal glycemic index. Am J Clin Nutr. 94 : 992-996.

Dong, JY., and Qin, LQ. (2011). Dietary glycemic index., glycemic load., and risk of breast cancer: meta-analysis of prospective cohort studies. Breast Cancer Res Treat. 126 : 287-294.

Egger, M., Smith, GD., and Phillips, AN. (1997). Meta-analysis: principles and procedures. BMJ 315 : 1533-1537.

Foster-Powell, K., Holt, SH., and Brand-Miller, JC. (2002). International table of glycemic index and glycemic load values: 2002. Am J Clin Nutr $76: 5-56$.

Foster-Powell, K., and Miller, JB. (1995). International tables of glycemic index. Am J Clin Nutr 62 : 871S-890S. 
Frazier, AL., Li, L., Cho, E., Willett, WC., and Colditz, GA. (2004). Adolescent diet and risk of breast cancer. Cancer Causes Control 15 : $73-$ 82.

Giles, GG., Simpson, JA., English, DR., Hodge, AM., Gertig, DM., Macinnis, RJ., and Hopper, JL. (2006). Dietary carbohydrate., fibre., glycaemic index., glycaemic load and the risk of postmenopausal breast cancer. Int J Cancer. 118 : 1843-1847.

Higginbotham, S., Zhang, ZF., Lee, IM., Cook, NR., Buring, JE., and Liu, S. (2004). Dietary glycemic load and breast cancer risk in the Women's Health Study. Cancer Epidemiol Biomarkers Prev.13 : 65-70.

Higgins, JP., and Thompson, SG. (2002). Quantifying heterogeneity in a meta-analysis. Stat Med. 21 : 1539-1558.

Holmes, MD., Liu, S., Hankinson, SE., Colditz, GA., Hunter, DJ., and Willett, WC. (2004). Dietary carbohydrates, fiber, and breast cancer risk. Am J Epidemiol. 159 : 732-739.

Jenkins, DJ., Wolever, TM., Taylor, RH., Barker, H., Fielden, H., Baldwin, JM., Bowling, AC., Newman, HC., Jenkins, AL., and Goff, DV. (1981). Glycemic index of foods: a physiological basis for carbohydrate exchange. Am J Clin Nutr. 34 : 362-366.

Jonas, CR., McCullough, ML., Teras, LR., Walker-Thurmond, KA., Thun, MJ., and Calle, EE. (2003). Dietary glycemic index, glycemic load, and risk of incident breast cancer in postmenopausal women. Cancer Epidemiol Biomarkers Prev.12 : 573-577.

Key, TJ. (2001). Glycemic index., hyperinsulinemia., and breast cancer risk. Ann Oncol. 12 : 1507-1509.

Lajous, M., Boutron-Ruault, MC., Fabre, A., Clavel-Chapelon, F., and Romieu, I. (2008) Carbohydrate intake, glycemic index, glycemic load, and risk of postmenopausal breast cancer in a prospective study of French women. Am J Clin Nutr 87 : 1384-1391. 
Larsson, SC., Bergkvist, L., and Wolk, A. (2009). Glycemic load, glycemic index and breast cancer risk in a prospective cohort of Swedish women. Int J Cancer. 125 : 153-157.

Li, BD., Khosravi, MJ., Berkel, HJ., Diamandi, A., Dayton, MA., Smith, M., and Yu, H. (2001). Free insulin-like growth factor-I and breast cancer risk. Int J Cancer. 91 : 736-739.

Linos, E., Willett, WC., Cho, E., and Frazier, L. (2010). Adolescent diet in relation to breast cancer risk among premenopausal women. Cancer Epidemiol Biomarkers Prev. 19 : 689-696.

Macaskill, P., Walter, SD., and Irwig, L. (2001). A comparison of methods to detect publication bias in meta-analysis. Stat Med. 20 : 641-654. Mulholland, HG., Murray, LJ., Cardwell, CR., and Cantwell, MM. (2008). Dietary glycaemic index., glycaemic load and breast cancer risk: a systematic review and meta-analysis. Br J Cancer. $99: 1170-1175$.

Nielsen, TG., Olsen, A., Christensen, J., Overvad, K., and Tjønneland, A. (2005). Dietary carbohydrate intake is not associated with the breast cancer incidence rate ratio in postmenopausal Danish women. J Nutr. 135 : 124-128.

Papa, V., and Belfiore, AJ. (1996). Insulin receptors in breast cancer: biological and clinical role. J Endocrinol Invest. 19 : $324-333$.

Pi-Sunyer, FX. (2002). Glycemic index and disease. Am J Clin Nutr 76 : 290S-298S.

Salmerón, J., Ascherio, A., Rimm, EB., Colditz, GA., Spiegelman, D., Jenkins, DJ., Stampfer, MJ., Wing, AL., and Willett, WC. (1997). Dietary fiber, glycemic load, and risk of NIDDM in men. Diabetes Care 20 : 545-550. 
Salmerón, J., Manson, JE., Stampfer, MJ., Colditz, GA., Wing, AL., and Willett, WC. (1997). Dietary fiber., glycemic load., and risk of noninsulin-dependent diabetes mellitus in women. JAMA. $277: 472-477$.

Shikany, JM., Redden, DT., Neuhouser, ML., Chlebowski, RT., Rohan, TE., Simon, MS., Liu, S., Lane, DS., and Tinker, L. (2011). Dietary glycemic load., glycemic index., and carbohydrate and risk of breast cancer in the Women's Health Initiative. Nutr Cancer. 63 : $899-907$.

Sieri, S., Pala, V., Brighenti, F., Pellegrini, N., Muti, P., Micheli, A., Evangelista, A., Grioni, S., Contiero, P., Berrino, F., and Krogh V. (2007). Dietary glycemic index, glycemic load, and the risk of breast cancer in an Italian prospective cohort study. Am J Clin Nutr. 86 : $1160-1166$. Silvera, SA., Jain, M., Howe, GR., Miller, AB., and Rohan, TE. (2005). Dietary carbohydrates and breast cancer risk: a prospective study of the roles of overall glycemic index and glycemic load. Int J Cancer. 114 : 653-658.

Stroup, DF., Berlin, JA., Morton, SC., Olkin, I., Williamson, GD., Rennie, D., Moher, D., Becker, BJ., Sipe, TA., and Thacker, SB. (2000). Meta-analysis of observational studies in epidemiology: a proposal for reporting. Meta-analysis Of Observational Studies in Epidemiology (MOOSE) group. JAMA $283: 2008-2012$.

van Houwelingen, HC., Arends, LR., and Stijnen, T. (2002). Advanced methods in meta-analysis: multivariate approach and meta-regression.

Stat Med. 21 : 589-624.

Viechtbauer, W. (2010). Conducting meta-analyses in R with the metafor package. J Stat Softw. 36 : 1-48.

WCRF. World Cancer Research Fund. (2007). In : Food., Nutrition., Physical Activity and the Prevention of Cancer: a Global Perspective. edn 2. American Institute for Cancer Research. Washington. USA. 
Wen, W., Shu, XO., Li, H., Yang, G., Ji, BT., Cai, H., Gao, YT., and Zheng, W. (2009). Dietary carbohydrates, fiber, and breast cancer risk in Chinese women. Am J Clin Nutr. 89 : 283-289.

Wolever, TM., Brand-Miller, JC., Abernethy, J., Astrup, A., Atkinson, F., Axelsen, M., Björck, I., Brighenti, F., Brown, R., Brynes, A., Casiraghi, MC., Cazaubiel, M., Dahlqvist, L., Delport, E., Denyer, GS., Erba, D., Frost, G., Granfeldt, Y., Hampton, S., Hart, VA., Hätönen, KA., Henry, CJ., Hertzler, S., Hull, S., Jerling, J., Johnston, KL., Lightowler, H., Mann, N., Morgan, L., Panlasigui, LN., Pelkman, C., Perry, T., Pfeiffer, AF., Pieters, M., Ramdath, DD., Ramsingh, RT., Robert, SD., Robinson, C., Sarkkinen, E., Scazzina, F., Sison, DC., Sloth, B., Staniforth, J., Tapola, N., Valsta, LM., Verkooijen, I., Weickert, MO., Weseler, AR., Wilkie, P., Zhang, J. (2008). Measuring the glycemic index of foods: interlaboratory study. Am J Clin Nutr 87 : 247S-257S. 


\section{Table legends}

Table 1. Main characteristics of cohort studies included in the meta-analysis, ranked by year of publication.

Table 2. Summary of results of meta-analyses on breast cancer glycemic index and glycemic load (metric used: high versus low glycemic index and glycemic load).

\section{Figure legends}

Figure 1. Flow chart of the literature search strategy to identify studies on breast cancer and glycemic index and glycemic load.

Figure 2. Forest plot relating glycemic index to breast cancer in cohort studies.

Figure 3. Forest plot relating glycemic load to breast cancer in cohort studies. 
Table 1. Main characteristics of cohort studies included in the meta-analysis, ranked by year of publication.

\begin{tabular}{|c|c|c|c|c|c|c|c|c|c|c|c|}
\hline \multirow{2}{*}{$\begin{array}{c}\text { Author, year of } \\
\text { publication }\end{array}$} & \multirow{2}{*}{ Country } & \multirow{2}{*}{ Study name } & \multirow{2}{*}{ Stratification } & \multirow{2}{*}{ Cases } & \multirow{2}{*}{ Total subjects } & \multirow{2}{*}{$\begin{array}{l}\text { Follow- } \\
\text { up in } \\
\text { years }\end{array}$} & \multirow{2}{*}{$\begin{array}{c}\text { Age at } \\
\text { entry }\end{array}$} & \multicolumn{2}{|c|}{ Glycemic index } & \multicolumn{2}{|c|}{ Glycemic load } \\
\hline & & & & & & & & $\begin{array}{c}\text { Range in } \\
\text { units }^{\mathrm{d}}\end{array}$ & RR $(95 \% \mathrm{CI})$ & Range in $g /$ day $^{d}$ & RR (95\% CI) \\
\hline Jonas, 2003 & USA & $\begin{array}{l}\text { Cancer Prevention Study II } \\
\text { Nutrition Cohort }\end{array}$ & PostM & 1,442 & 63,307 & 5 & $40-87$ & $65-85$ & $1.03(0.87-1.22)$ & $83-147$ & $0.90(0.76-1.07)$ \\
\hline Cho, 2003 & USA & Nurses' Health Study II & PreM & 714 & 90,655 & 8 & $26-46$ & $70-82$ & $1.05(0.83-1.33)$ & $138-211$ & $1.06(0.78-1.45)$ \\
\hline Holmes, 2004 & USA & Nurses' Health Study & \begin{tabular}{|l|} 
PreM \\
PostM \\
\end{tabular} & $\begin{array}{c}852 \\
2,924 \\
\end{array}$ & $\begin{array}{l}53,891 \\
76,200 \\
\end{array}$ & $\begin{array}{l}18 \\
18 \\
\end{array}$ & & $\begin{array}{c}69-81 \\
\text { NR } \\
\end{array}$ & $\begin{array}{l}1.02(0.82-1.28) \\
1.15(1.02-1.30) \\
\end{array}$ & $\begin{array}{c}116-186 \\
\text { NR } \\
\end{array}$ & $\begin{array}{l}0.87(0.70-1.12) \\
1.03(0.90-1.16) \\
\end{array}$ \\
\hline Frazier, 2004 & USA & Nurses' Health Study II & Pre and PostM & 838 & 47,355 & 8 & $25-42$ & $74-84$ & $1.47(1.04-2.08)$ & $202-289$ & $1.23(0.91-1.67)$ \\
\hline Silvera, 2005 & Canada & $\begin{array}{l}\text { National Breast Screening } \\
\text { Study }\end{array}$ & \begin{tabular}{|l} 
total \\
PreM \\
PostM
\end{tabular} & $\begin{array}{c}1,461 \\
670 \\
575 \\
\end{array}$ & $\begin{array}{c}49,613 \\
\text { PY } 400,673 \\
\text { PY } 300,048\end{array}$ & $\begin{array}{l}17 \\
17 \\
17\end{array}$ & $40-59$ & $\begin{array}{l}<60->96 \\
<63->92 \\
<63->92\end{array}$ & $\begin{array}{l}0.88(0.63-1.22) \\
0.78(0.52-1.16) \\
1.87(1.18-2.97)\end{array}$ & $\begin{array}{l}<119->175 \\
<125->169 \\
<125->169\end{array}$ & $\begin{array}{l}0.95(0.79-1.14) \\
0.96(0.76-1.22) \\
1.08(0.82-1.41)\end{array}$ \\
\hline Nielsen, 2005 & Denmark & $\begin{array}{l}\text { Diet, Cancer, and Health } \\
\text { study }\end{array}$ & $\begin{array}{l}\text { PostM } \\
\text { ER+ }^{\mathrm{c}} \\
\text { ER- }^{c}\end{array}$ & $\begin{array}{l}634 \\
456 \\
122 \\
\end{array}$ & 23,870 & 4 & $50-65$ & $\begin{array}{l}\mathrm{NR} \\
\mathrm{NR} \\
\mathrm{NR} \\
\end{array}$ & $\begin{array}{l}0.94(0.80-1.10)^{\mathrm{a}} \\
0.86(0.71-1.04)^{\mathrm{a}} \\
1.46(1.01-2.11)^{\mathrm{a}}\end{array}$ & $\begin{array}{l}\mathrm{NR} \\
\mathrm{NR} \\
\mathrm{NR} \\
\end{array}$ & $\begin{array}{l}1.04(0.90-1.20)^{\mathrm{a}} \\
0.99(0.84-1.17)^{\mathrm{a}} \\
1.17(0.86-1.59)^{\mathrm{a}}\end{array}$ \\
\hline Giles, 2006 & Australia & $\begin{array}{l}\text { Melbourne Collaborative } \\
\text { Cohort Study }\end{array}$ & $\begin{array}{l}\text { PostM } \\
\text { ER+ }{ }^{c} \\
\text { ER- }^{c}\end{array}$ & $\begin{array}{c}324 \\
154 \\
52 \\
\end{array}$ & 12,273 & 4 & $40-69$ & $\begin{array}{c}46-53 \\
\text { NR } \\
\text { NR } \\
\end{array}$ & $\begin{array}{l}0.95(0.79-1.14)^{b} \\
0.79(0.60-1.02)^{b} \\
0.95(0.61-1.48)^{b}\end{array}$ & $\begin{array}{c}77-150 \\
\text { NR } \\
\text { NR } \\
\end{array}$ & $\begin{array}{l}1.56(1.05-2.31)^{\mathrm{b}} \\
1.31(0.74-2.31)^{\mathrm{b}} \\
0.58(0.23-1.45)^{\mathrm{b}}\end{array}$ \\
\hline Sieri, 2007 & Italy & Hormones and Diet Study & \begin{tabular}{|l} 
total \\
PreM \\
PostM
\end{tabular} & $\begin{array}{l}289 \\
146 \\
128 \\
\end{array}$ & 8,926 & 5 & $34-70$ & $\begin{array}{l}52-59 \\
\text { NR } \\
\text { NR }\end{array}$ & $\begin{array}{l}1.57(1.04-2.36) \\
1.82(1.01-3.27) \\
1.12(0.62-2.02) \\
\end{array}$ & $\begin{array}{c}97-151 \\
\text { NR } \\
\text { NR } \\
\end{array}$ & $\begin{array}{l}2.53(1.54-4.16) \\
3.89(1.81-8.34) \\
1.67(0.80-3.46) \\
\end{array}$ \\
\hline Lajous, 2008 & France & E3N French study & $\begin{array}{l}\text { PostM } \\
\text { ER+ }{ }^{c} \\
\text { ER- }^{c}\end{array}$ & $\begin{array}{c}1,812 \\
1,083 \\
279\end{array}$ & 62,739 & 9 & $40-65$ & $\begin{array}{c}44-66 \\
\text { NR } \\
\text { NR }\end{array}$ & $\begin{array}{l}1.14(0.99-1.32) \\
1.05(0.88-1.27) \\
0.91(0.63-1.32)\end{array}$ & $\begin{array}{c}84-165 \\
\text { NR } \\
\text { NR }\end{array}$ & $\begin{array}{l}1.11(0.96-1.29) \\
0.91(0.75-1.11) \\
1.55(1.07-2.25)\end{array}$ \\
\hline Larsson, 2009 & Sweden & $\begin{array}{l}\text { Swedish Mammography } \\
\text { Cohort }\end{array}$ & $\begin{array}{l}\text { Pre and PostM } \\
\text { ER }+^{c} \\
\text { ER- }^{c}\end{array}$ & $\begin{array}{c}2,952 \\
1,286 \\
266\end{array}$ & 61,433 & 17 & $40-75$ & $\begin{array}{l}76-83 \\
76-83 \\
76-83\end{array}$ & $\begin{array}{c}1.08(0.96-1.21) \\
0.89(0.74-1.06) \\
1.29(0.85-1.96)\end{array}$ & $\begin{array}{l}164-200 \\
164-200 \\
164-200\end{array}$ & $\begin{array}{l}1.13(1.00-1.29) \\
0.94(0.77-1.13) \\
1.23(0.79-1.90)\end{array}$ \\
\hline Wen, 2009 & China & $\begin{array}{l}\text { ShanghaiWomen's Health } \\
\text { Study }\end{array}$ & \begin{tabular}{|l} 
total \\
PreM \\
PostM
\end{tabular} & $\begin{array}{l}616 \\
190 \\
426\end{array}$ & 74,942 & 7 & $40-70$ & $\begin{array}{l}64-77 \\
64-77 \\
64-77\end{array}$ & $\begin{array}{l}1.03(0.79-1.34) \\
1.19(0.73-1.94) \\
0.96(0.70-1.31)\end{array}$ & $\begin{array}{l}164-240 \\
164-240 \\
164-240\end{array}$ & $\begin{array}{l}1.07(0.82-1.39) \\
1.53(0.96-2.45) \\
0.91(0.67-1.25)\end{array}$ \\
\hline Shikany, 2011 & USA & Women's Health Initiative & $\begin{array}{l}\text { PostM } \\
\text { ER }^{\mathrm{c}} \\
\text { ER- }^{c}\end{array}$ & $\begin{array}{c}6,115 \\
3,016 \\
616\end{array}$ & 148,767 & 8 & $50-79$ & $\begin{array}{c}48-57 \\
\text { NR } \\
\text { NR }\end{array}$ & $\begin{array}{l}1.01(0.91-1.12) \\
1.05(0.90-1.22) \\
1.07(0.74-1.52)\end{array}$ & $\begin{array}{c}53-150 \\
\text { NR } \\
\text { NR }\end{array}$ & $\begin{array}{l}1.08(0.92-1.29) \\
0.81(0.63-1.04) \\
1.68(0.93-3.02)\end{array}$ \\
\hline
\end{tabular}

URL: http://mc.manuscriptcentral.com/bfsn Email: fergc@foodsci.umass.edu 
Table 2. Summary of results of meta-analyses on breast cancer glycemic index and

\section{glycemic load (metric used: high versus low glycemic index and glycemic load).}

\begin{tabular}{|c|c|c|c|c|c|c|c|}
\hline \multirow{2}{*}{ Analysis } & \multirow{2}{*}{ Number of studies } & \multirow{2}{*}{ Summary estimate } & \multirow{2}{*}{$95 \% \mathrm{CI}$} & \multirow{2}{*}{$\mathbf{I}^{2}$} & \multicolumn{3}{|c|}{ Publication bias (p-value) } \\
\hline & & & & & Begg & Egger & Macaskill \\
\hline \multicolumn{8}{|c|}{ Glycemic index } \\
\hline All studies & 12 & 1.05 & 1.001 .11 & $20 \%$ & 0.73 & 0.93 & 0.88 \\
\hline \multicolumn{8}{|c|}{ Heterogeneity analysis } \\
\hline \multicolumn{8}{|l|}{ Adjustments } \\
\hline Age-adjusted RR & $8^{\#}$ & 0.99 & 0.911 .08 & $52 \%$ & 0.62 & 0.49 & 0.76 \\
\hline Fully-adjusted RR ${ }^{*}$ & $8^{\#}$ & 1.05 & 0.981 .12 & $19 \%$ & 0.46 & 0.77 & 0.79 \\
\hline \multicolumn{8}{|l|}{ Menopausal status } \\
\hline Premenopausal & 5 & 1.04 & $0.86 \quad 1.27$ & $31 \%$ & 0.33 & 0.83 & 0.68 \\
\hline Postmenopausal & 9 & 1.05 & $0.98 \quad 1.13$ & $40 \%$ & 0.53 & 0.99 & 0.96 \\
\hline \multicolumn{8}{|l|}{ ER status } \\
\hline ER+ & 5 & 0.94 & $0.83 \quad 1.08$ & $36 \%$ & 0.62 & 0.14 & 0.11 \\
\hline ER- & 5 & 1.12 & $0.88 \quad 1.43$ & $5 \%$ & 0.33 & 0.89 & 0.72 \\
\hline \multicolumn{8}{|c|}{ Glycemic load } \\
\hline All studies & 12 & 1.06 & 1.001 .13 & $55 \%$ & 0.58 & 0.41 & 0.50 \\
\hline \multicolumn{8}{|c|}{ Heterogeneity analysis } \\
\hline \multicolumn{8}{|l|}{ Adjustments } \\
\hline Age-adjusted RR & $8^{\#}$ & 1.02 & 0.961 .08 & $4 \%$ & 0.46 & 0.17 & 0.48 \\
\hline Fully-adjusted RR* & $8^{\#}$ & 1.05 & $0.98 \quad 1.13$ & $3 \%$ & 0.46 & 0.35 & 0.76 \\
\hline \multicolumn{8}{|l|}{ Menopausal status } \\
\hline Premenopausal & 5 & 1.23 & 0.752 .00 & $76 \%$ & 0.33 & 0.02 & 0.78 \\
\hline Postmenopausal & 9 & 1.05 & $0.97 \quad 1.13$ & $21 \%$ & 0.60 & 0.87 & 0.78 \\
\hline \multicolumn{8}{|l|}{ ER status } \\
\hline ER+ & 5 & 0.94 & 0.821 .07 & $0 \%$ & 0.33 & 0.40 & 0.06 \\
\hline ER- & 5 & 1.28 & $0.98 \quad 1.68$ & $21 \%$ & 0.62 & 0.76 & 0.21 \\
\hline $\begin{array}{l}\text { * All studies adjusted } \\
\text { menopausal status, o } \\
\text { use. }\end{array}$ & $\begin{array}{l}\text { or BMI. All except } \Gamma \\
\text { contraceptive use, }\end{array}$ & $\begin{array}{l}\text { Tielsen, } 2005 \text { adjustme } \\
\text { amilial history of brea }\end{array}$ & $\begin{array}{l}\text { ent for age at } \\
\text { ist cancer, to }\end{array}$ & $\begin{array}{l}\text { it basel } \\
\text { otal en }\end{array}$ & $\begin{array}{l}\text { line, ag } \\
\text { ergy in }\end{array}$ & $\begin{array}{l}\text { at men } \\
\text { ake, and }\end{array}$ & $\begin{array}{l}\text { arche, } \\
\text { alcohol }\end{array}$ \\
\hline
\end{tabular}




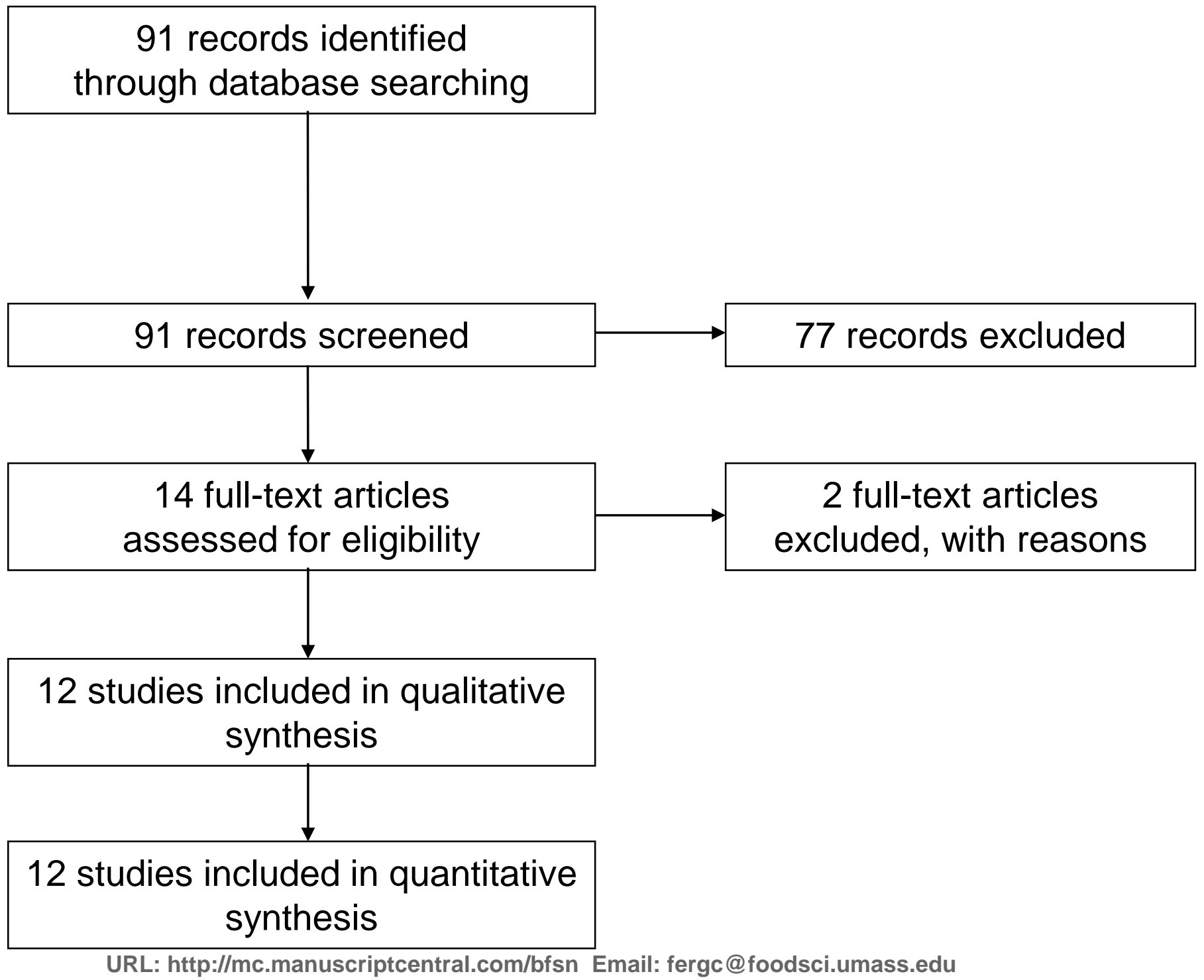


Jonas, 2003

Cho, 2003

Holmes, 2004

Frazier, 2004

Silvera, 2005

Nielsen, 2005

Giles, 2006

Sieri, 2007

Lajous, 2008

Larsson, 2009

Wen, 2009

Shikany, 2011

Summary RR

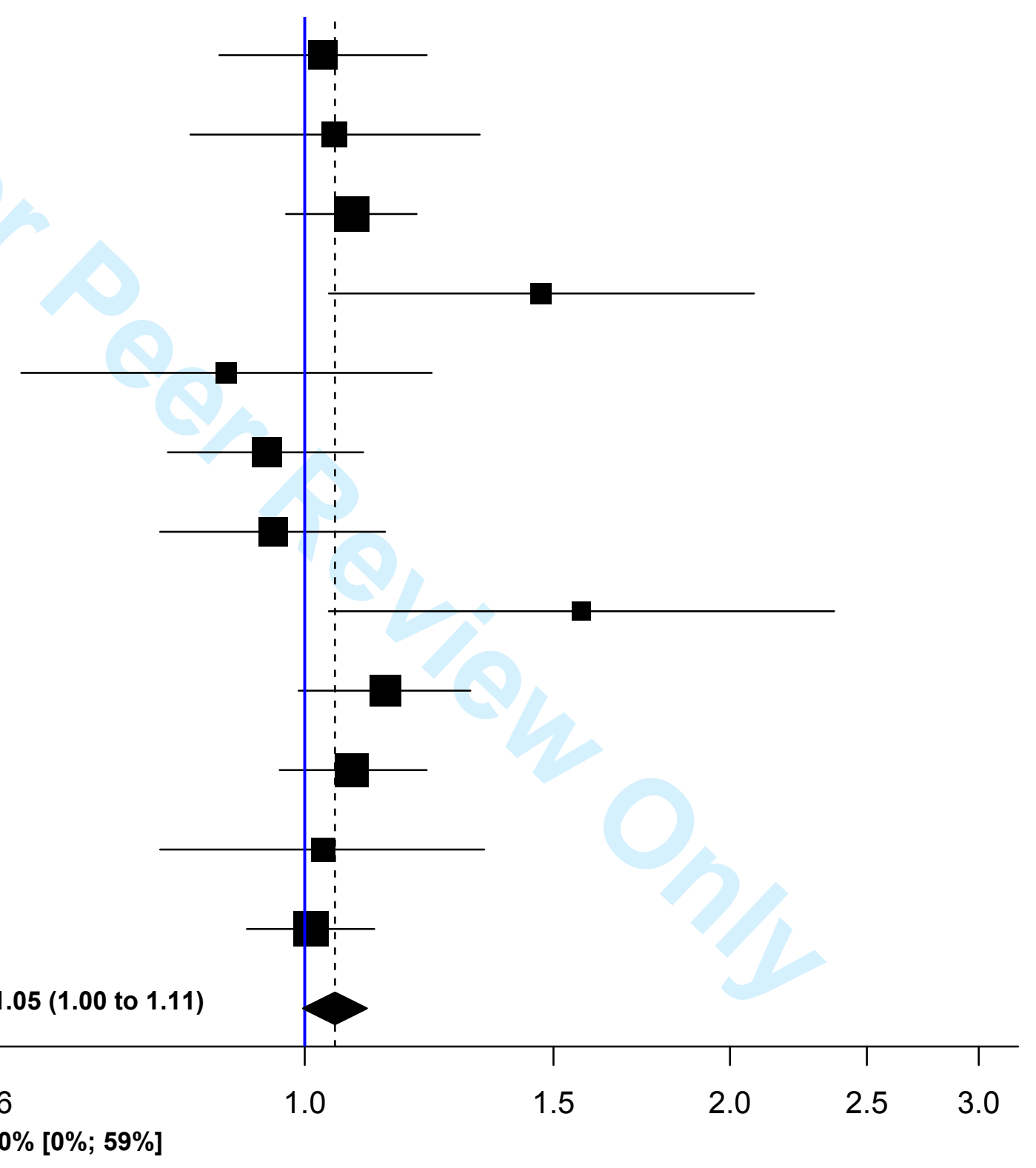


Jonas, 2003

Cho, 2003

Holmes, 2004

Frazier, 2004

Silvera, 2005

Nielsen, 2005

Giles, 2006

Sieri, 2007

Lajous, 2008

Larsson, 2009

Wen, 2009

Shikany, 2011

Summary RR

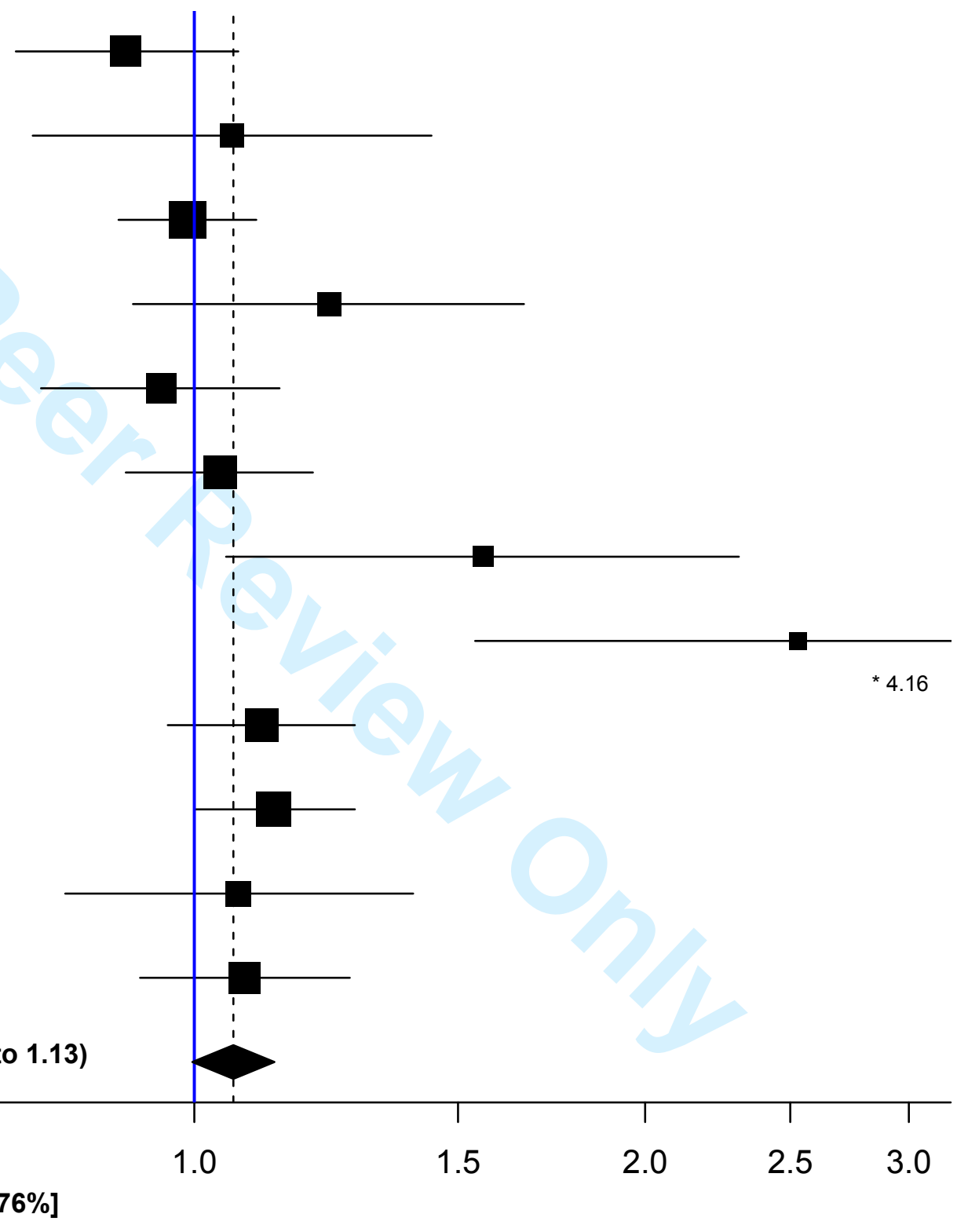

